(2) Open Access Full Text Article

\title{
Histopathological and electron microscopic study for different grades of inferior oblique muscle overaction
}

This article was published in the following Dove Press journal:

Clinical Ophthalmology

20 May 2013

Number of times this article has been viewed

\author{
Momen M Hamdi \\ Golzamine R El-Hawary' \\ Nadia G El-Hefnawy ${ }^{2}$ \\ Manal I Salman² \\ 'Ophthalmology Department, \\ 2Pathology Department, Faculty \\ of Medicine, Ain Shams University, \\ Cairo, Egypt
}

Purpose: To correlate between the clinical degree of inferior oblique muscle (IO) overaction and the histopathological changes of the muscle.

Settings: Departments of Ophthalmology and Pathology, Faculty of Medicine, Ain Shams University, Cairo, Egypt.

Patients and methods: Biopsies from 12 IO muscles were taken during strabismus surgery for cases of IO muscle overaction. One biopsy from a normal IO was taken as a control. All samples were examined under light microscopy and transmission electron microscopy.

Results: In light microscopy, all cases showed histopathological changes, in the form of degenerated and regenerating muscle fibers, increased fibrofatty infiltration, and mild variability of muscle fiber size. Hypertrophied nerve bundles also appeared in biopsies from patients with grade II and grade III IO overaction. Endomysial and perimysial fibrosis, mononuclear inflammatory infiltrates, and focal fatty infiltration were seen in biopsies from cases of grade III IO overaction. In electron microscopy, ultrastructural examination revealed an increased number of mitochondria associated with some degree of mitochondrial pleomorphism. Hypercontracted fibers, vacuoles, and fat droplets were also noticed.

Conclusion: IO overaction is always accompanied by histopathological changes that differ in severity according to the clinical grading of the overaction. Changes in nerve fibers can also occur in severe cases.

Keywords: inferior oblique, electron microscope, overaction, histopathological, muscle fibers

\section{Introduction}

Disturbances of ocular motility often include inferior oblique (IO) muscle overaction, which, clinically, is classified into primary and secondary types. ${ }^{1}$ The primary type is of unknown cause and is usually bilateral, whereas the secondary type is usually unilateral. ${ }^{1}$ A secondary cause is weakness of IO muscle's direct antagonist, the superior oblique muscle, which may be congenital or acquired. IO overaction might also be due to the weakness of IO muscle's contralateral synergist, the superior rectus muscle. ${ }^{2,3}$

IO overaction can be graded clinically from I to III. Grade I presents mild overaction, only noticed in the extreme "up-in" gaze. Grade II presents moderate overaction, seen in the "adducted" gaze. Grade III shows severe overaction seen in the primary gaze.

Biopsy can be easily taken from the IO muscle without causing any undesirable results during myectomy. This facilitates histopathological examination. ${ }^{5}$
Correspondence: Momen Mahmoud Hamdi,Ains Shams University, 2 Ahmed El-Khashab St, Nasr City, 8th Region, Cairo II47I, Egypt Tel +20 I22 3532717

Email mo2_76@hotmail.com; momen. ibrahim@magrabi.com.sa 
The extraocular muscles (EOMs) are comprised of striated muscle fibers, separated by connective tissue (epimysium). Each fiber has a sheath (the sarcolemma). The fiber unit contains the contractile tissue (the myofibrils), the nucleus, and the ground substance (the sarcoplasm) which contain the organels. ${ }^{3}$

Histologically, EOMs, with a unique two-fiber system, differ from the other skeletal muscles. Resembling the usual skeletal muscle is the "fibrillenstruktur" fiber, which contains small, well-organized myofibrils surrounded by abundant sarcoplasm, large concentrations of mitochondria, and a nucleus that is usually situated peripherally. Each sarcomere has an orderly tubular (T) system. The unique striated muscle fiber found in the EOMs is the "felderstruktur" fiber, containing large, partially fused myofibrils embedded in scanty cytoplasm, a virtual absence of concentrations of mitochondria, and a nucleus that is usually located centrally. The sarcomeres are nearly devoid of a T system. Electron microscopy of both types of fibers reveals their histological differences. Light microscopy of a transverse section of an EOM shows the "fibrillenstruktur" fibers staining palely with regularly spaced myofibrils, while the "felderstruktur" fibers stain more densely, with irregularly clumped myofibrils. ${ }^{6}$

The present study aimed to investigate the histopathological and electron microscopic changes that occur in different grades of IO overaction and correlate them to the degree of overaction.

\section{Patients and methods}

The study included biopsies of twelve IO muscles, collected during strabismus surgery from seven patients (unilateral biopsy from two and bilateral biopsies from five). All cases were chosen from the strabismus specialized clinic at Ain Shams University hospitals, Cairo, Egypt.

The cases belonged to two clinical groups, moderate and severe (grade II and III, respectively), since grade I is not a candidate for surgical intervention. For comparison, a biopsy was taken from a normal IO muscle of an enucleated eye. Written consent was obtained by the patient or their legal representative, in adherence to the tenets of the Declaration of Helsinki. The study did not require prior approval from the Ain Sham University review board.

All specimens were collected by myectomy. The length of the excised segment depended on the degree of muscle overaction as diagnosed clinically. This was always in coordination with the operative findings in regards to the thickness and vascularity of the muscle.

The thickness of the IO muscle belly is not homogenous, so in myectomy we excised the part from the thickest area, usually in the middle part of the belly. The excised part ranged from 5-8 $\mathrm{mm}$ according to the clinical stage, which was always similar during surgery. Thus, in stage III, the muscle was thick and vascular so the excised portion was $7-8 \mathrm{~mm}$, whereas in stage II, the muscle was less thick, so the excised portion was $5-6 \mathrm{~mm}$.

\section{Microscopic examination}

All biopsy specimens were cut into cubes of $1 \mathrm{~mm}^{3}$ in size, fixed in formaldehyde/glutaraldehyde solution, then routinely processed and embedded in resin blocks for electron microscopic examination.

One-micron-thick, semi-thin sections were cut by the ultra-microtome and stained with toluidine blue for light microscopic examination, and $70 \mathrm{~nm}$-thick ultrathin sections were cut and stained by uranyl acetate and lead citrate. The ultrathin sections were then examined by a transmission electron microscope (EM400T, Phillips, Rotterdam, The Netherlands) at $80 \mathrm{kV}$ at the electron microscopy unit of the Ain Shams University Specialized Hospital.

\section{Results}

The mean age of the patients was $11.57 \pm 5$ years and ranged from 3 to 35 years. Among the seven patients, four (57.3\%) were male and three $(42.8 \%)$ were female.

Table 1 presents the clinical features and the histopathological findings of all cases.

\section{Histopathological findings}

\section{Light microscopic features}

Mild to moderate variability in muscle fiber size was seen in all biopsies (Figure 1A). Degenerated fibers, hypercontracted fibers (Figure 1B), and regenerating fibers (Figure 1C) were seen in seven out of twelve biopsies (58.3\%). Many round fibers (Figure 1A) were seen in three of the twelve biopsies $(25 \%)$, and focally split fibers were seen in two of the twelve biopsies (16.6\%). Focal fatty infiltration of the fibers was noted in one of the twelve biopsies (8.33\%). Mononuclear inflammatory cell infiltrate (Figure 1D) was noted in three of the twelve biopsies (25\%). Endomysial and perimysial fibroses (Figure 1C) were noted in three of the twelve biopsies (25\%). Prominent hypertrophied nerve bundles (Figure 1A-D) were seen in six of the twelve biopsies (50\%).

Among the above findings, endomysial and perimysial fibrosis, mononuclear inflammatory infiltrate, and focal fatty infiltration were seen in biopsies from cases of grade III only $(25 \%)$, whereas the rest of the findings were seen in 
Table I Clinical features of the patients

\begin{tabular}{|c|c|c|c|}
\hline Case no & Diagnosis and grade of overaction & Surgical procedure & Histopathological findings (LM) \\
\hline I & $\begin{array}{l}\text { Alternating accommodative esotropia } \\
\text { with bilateral IO overaction, grade II } \\
(\mathrm{Rt}>\mathrm{Lt})\end{array}$ & $\begin{array}{l}\text { Bilateral IO myectomy } \\
(\mathrm{Rt}>\mathrm{Lt})\end{array}$ & $\begin{array}{l}\text { Hypertrophied nerve bundles, few scattered } \\
\text { degenerated muscle fibers }\end{array}$ \\
\hline 2 & $\begin{array}{l}\text { Bilateral IO overaction, Rt grade II, } \\
\text { Lt grade III }\end{array}$ & $\begin{array}{l}\text { Bilateral IO myectomy } \\
(\mathrm{Lt}>\mathrm{Rt})\end{array}$ & $\begin{array}{l}\text { Endomysial fibrosis, perimysial fibrosis, moderate } \\
\text { variability in muscle fiber size } \\
\text { Interstitial mononuclear inflammatory cells, } \\
\text { degenerated fibers, regenerating fibers, large } \\
\text { vacuolar nuclei }\end{array}$ \\
\hline 3 & $\begin{array}{l}\text { Bilateral IO overaction, grade II } \\
(\mathrm{Lt}>\mathrm{Rt})\end{array}$ & $\begin{array}{l}\text { Bilateral IO myectomy } \\
(\mathrm{Lt}>\mathrm{Rt})\end{array}$ & $\begin{array}{l}\text { Hypertrophied nerve bundles, mild variability in } \\
\text { muscle fiber size, scattered degenerated fibers }\end{array}$ \\
\hline 4 & $\begin{array}{l}\text { Infantile alternating esotropia } \\
\text { Bilateral IO overaction, grade II }\end{array}$ & $\begin{array}{l}\text { Bilateral medial recession } \\
\text { Bilateral IO myectomy }\end{array}$ & $\begin{array}{l}\text { Hypertrophied nerve bundles, mild variability in } \\
\text { muscle fiber size, scattered degenerated fibers } \\
\text { Slight increase in number of mitochondria }\end{array}$ \\
\hline 5 & $\begin{array}{l}\text { Lt third nerve palsy with contralateral } \\
\text { IO overaction, grade III }\end{array}$ & $\begin{array}{l}\text { Lt lateral recession } \\
\text { Lt medial resection } \\
\text { Rt IO myectomy } \\
\text { Rt IR faden operation }\end{array}$ & $\begin{array}{l}\text { Endomysial fibrosis, mild variability in muscle fiber } \\
\text { size, focal infiltration by chronic inflammatory } \\
\text { cells, great increase in the mitochondria, fatty } \\
\text { infiltration of the muscle fibers (lipid vacuoles) }\end{array}$ \\
\hline 6 & Lt IO overaction, grade III & Lt IO myectomy & $\begin{array}{l}\text { Mild variability in muscle fiber size, focal splitting } \\
\text { of muscle fibers, degenerated hypercontracted } \\
\text { fibers, many rounded fibers, and increased } \\
\text { number of mitochondria }\end{array}$ \\
\hline 7 & $\begin{array}{l}\text { Infantile alternating esotropia } \\
\text { Bilateral IO overaction, grade II } \\
(\mathrm{Rt}>\mathrm{Lt})\end{array}$ & $\begin{array}{l}\text { Bilateral medial recession } \\
\text { Bilateral IO myectomy } \\
(\mathrm{Rt}>\mathrm{Lt})\end{array}$ & $\begin{array}{l}\text { Endomysial fibrosis, perimysial fibrosis, moderate } \\
\text { variability in muscle fiber size, interstitial } \\
\text { mononuclear inflammatory cells, and } \\
\text { hypertrophied nerve bundles }\end{array}$ \\
\hline
\end{tabular}

Abbreviations: IO, inferior oblique; IR, inferior rectus; LM, light microscope; Lt, left; Rt, right.

biopsies from cases of both grade II and grade III, but they were more profound in grade III.

\section{Electron microscopic features}

Many fibers contained numerous mitochondria. The mitochondria showed mild pleomorphism and dense matrix (Figure 2A).

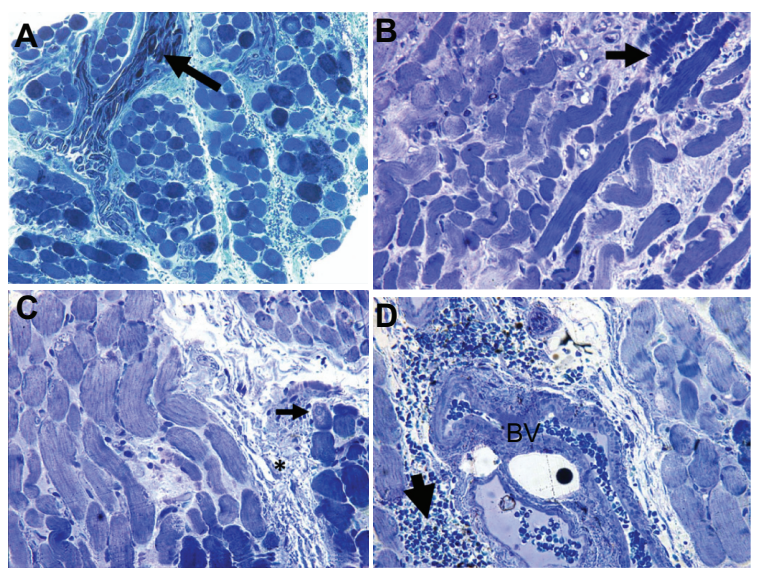

Figure I Light microscopic findings of inferior oblique muscle biopsies. (A) Variability in muscle fiber size, some round fibers and hypertrophied nerve bundles (arrow). (B) Hypercontracted fibers (arrow). (C) Endomysial and perimysial fibrosis $(*)$ and regenerating fibers with vesicular nuclei and prominent nucleoli (arrow). (D) Perivascular mononuclear inflammatory cell infiltrate (arrow) around blood vessels (BV).

Notes: Toluidine blue $(\mathbf{A}$ and $\mathbf{B}) \times 100,(\mathbf{C}$ and $\mathbf{D}) \times 200$.
They formed subsarcolemmal aggregates or were found dispersed between the myofilaments (Figure 2B and C).

Some fibers were hypercontracted and contained many vacuoles, including lipid ones (Figure 2D). Disarray of myofilaments along with focal loss was also noted in some fibers. Some fibers showed large vesicular nuclei with prominent nucleoli (Figure 2E). Degenerated mitochondria with vacuolation were also noted by higher magnification (Figure 2F).

These findings were noted in biopsies from cases of both clinical grades II and III, but they were more profound in grade III.

\section{Discussion}

Vertical strabismus can result from primary and secondary IO overaction. Suitable biopsies can be taken easily from this muscle without adverse effects. This allows its histopathological examination by light and electron microscopy. ${ }^{5}$

The current study included twelve biopsies of IO muscles from patients complaining of unilateral or bilateral vertical strabismus of different etiologies. Nine out of twelve biopsies (75\%) belonged to grade II and three out of twelve biopsies (25\%) belonged to grade III. All biopsies examined showed histopathological and ultrastructural abnormalities. 


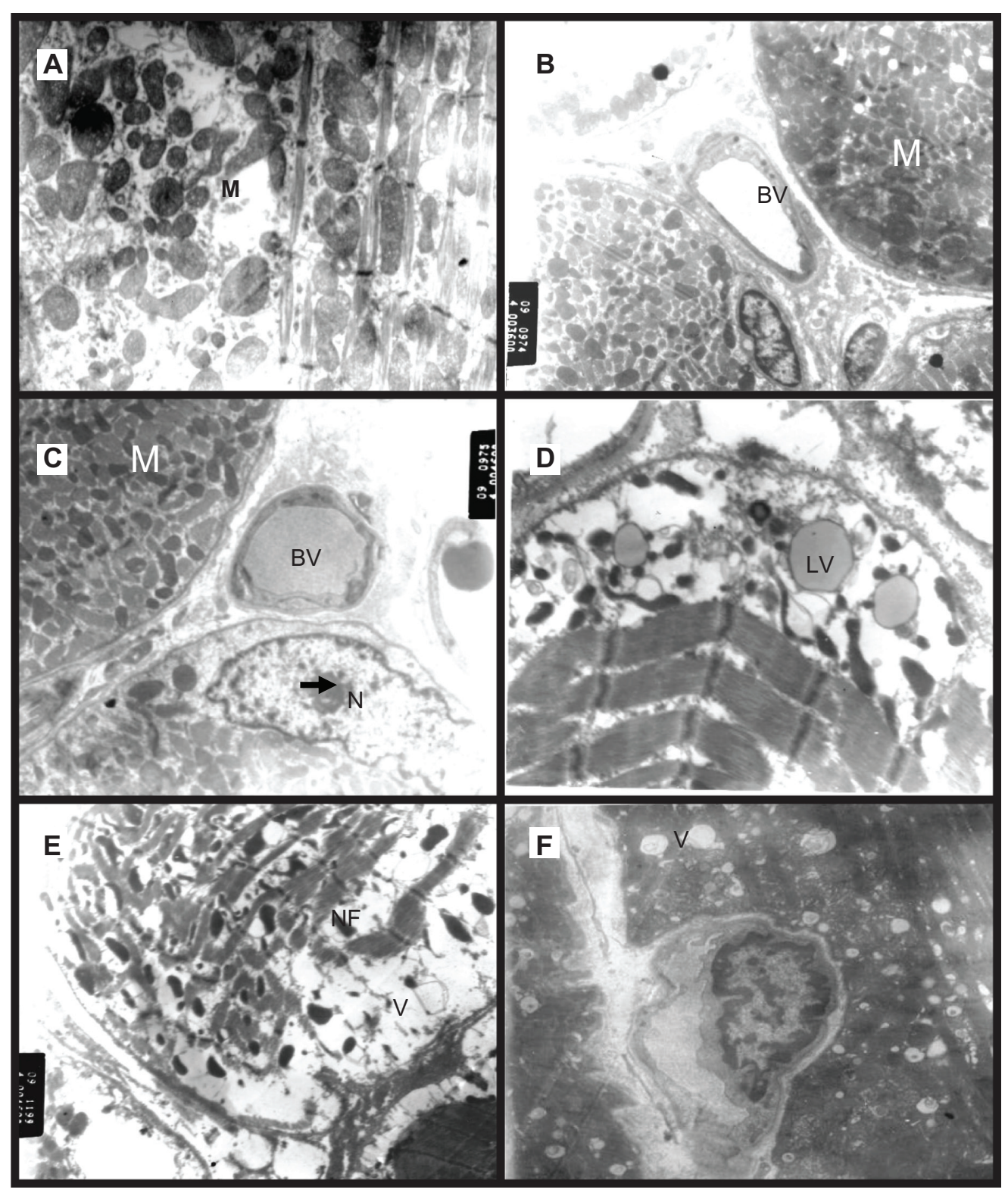

Figure 2 Electron microscopic findings in inferior oblique muscle biopsies. (A) The mitochondria are pleomorphic with focal degenerative changes and loss of cristae. (B and C) Frequent mitochondria (M) with subsarcolemmal aggregates. Large open-face nucleus $(\mathrm{N})$ with a prominent nucleolus (arrow) and blood vessels (BV) can also be seen. (D) Lipid vacuoles (LV) can be seen. (E) Subsarcolemmal vacuoles and necrotic fibrils (NF). (F) Degenerated mitochondria with vacuolation (V).

Notes: Uranyl acetate \& lead citrate X4000 (A,B,C and E) and X8000 (D and F)

The striking histopathological features included: degenerated fibers and regenerating ones; mild to moderate variability in muscle fiber size, along with hypercontracted fibers; some round fibers; and focal splitting of some others. Ultrastructural examination also revealed degenerative changes in the fibers along with regenerating ones with large vesicular nuclei. Similar findings were reported by Meyer et al, ${ }^{1}$ Martinez et al, ${ }^{7}$ and Spencer and $\mathrm{McNeer}^{8}$ in their studies of primary and secondary IO overaction. They found by light microscopy the presence of granular fibers with sarcoplasmic masses, and also noted that some fibers showed various stages of atrophy. Moreover, in 1992, Choi and Chang studied overacting IO muscle by light and electron microscope and noted variability of muscle fiber size with vacuolation and degeneration. ${ }^{3}$

More profound degenerative changes were also noted in biopsies from grade III in the current research, since we found focal fatty infiltration and perimysial and endomysial fibrosis in these cases.

The persistent contraction of the IO muscle due to the loss of equilibrium resulting from the weakness of its antagonist 
may result in such degenerative changes in the muscle fibers. Consequent activation of satellite cells may follow, with the appearance of new regenerating fibers resulting in the variability in the size of muscle fibers. ${ }^{9}$

Focal mononuclear inflammatory cell infiltrate was also noted in some cases with grade III in the current study. This may be related to an inflammatory response following necrosis of some fibers.

Vacuoles, including fat vacuoles, were also noted in some cases. Supporting these results, other authors have found by ultrastructural examination increased vacuolation. ${ }^{1,3,7,8}$ Meyer et al claimed that most of these vacuoles represented dilated endoplasmic reticulum or empty mitochondria. ${ }^{1}$

Mitochondrial aggregates and pleomorphism were also profound findings in the current study, mainly in grade III. In agreement with this finding, Meyer et al, ${ }^{1}$ Choi and Chang, ${ }^{3}$ and Spencer and $\mathrm{McNeer}^{8}$ concluded that mitochondrial aggregation and degeneration were the striking features in their studies. This finding may result from the degenerative and regenerative changes in the fibers. It may also result from the relative abundance of singly innervated muscle fibers (SIF), which are characterized by mitochondrial abundance.

Hypertrophied nerve bundles were also seen in some cases in the present study. No similar results were obtained from other studies. However, this finding may be related to an increase of the number of SIF innervated fibers in the hypertrophied overacting IO muscle. These SIFs are fast, twitchgenerating, and specialized for intense oxidative metabolism and fatigue resistance. ${ }^{9}$ In addition, Berard-Badier et al in 1978 confirmed on the presence of subsarcolemmal inclusions of granular fibrillar aggregates. ${ }^{10}$

\section{Conclusion}

From this study it could be concluded that overactive IO always show histopathological and ultrastructural abnormalities including hypertrophied nerve bundles, which are more profound in grade III. These changes correlate to the clinical grade of overaction. According to our knowledge, this research is so far the first to emphasize such changes in IO muscle fibers and the correlation between histopathological changes and clinical grading of IO overaction.

\section{Disclosure}

The authors report no conflicts of interest in this work.

\section{References}

1. Meyer E, Ludatscher RM, Zonis S. Primary and secondary overacting inferior oblique muscles: an ultrastructural study. $\mathrm{Br} J$ Ophthalmol. 1984;68(6):416-420.

2. Lennerstrand G. Strabismus and eye muscle function. Acta Ophthalmol Scand. 2007;85(7):711-723.

3. Choi DG, Chang BL. Electron microscopic study on overacting inferior oblique muscles. Korean J Ophthalmol. 1992;6(2):69-75.

4. Porter JD, Baker RS, Ragusa RJ, Bruekner JK. Extraocular muscles: basic and clinical aspects of structure and function. Surv Ophthalmol. 1995;39(6):451-484.

5. Hoogenraad TU, Tan KE, Eelderink HJ, Veldman H, Jennekens FG. The inferior oblique as muscle of choice for biopsies of extraocular muscles. Br J Ophthalmol. 1979;63(10):680-683.

6. Ruff RL. More than meets the eye: extraocular muscle is very distinct from extremity skeletal muscle. Muscle Nerve. 2002;25(3):311-313.

7. Martinez AJ, Biglan AW, Hiles DA. Structural features of extraocular muscles of children with strabismus. Arch Ophthalmol. 1980;98(3): 533-539.

8. Spencer RF, McNeer KW. Structural alterations in overacting inferior oblique muscles. Arch Ophthalmol. 1980;98(1):128-133.

9. Magaudda L, Mauro DD, Trimarchi F, Anastasi G. Effects of physical exercise on skeletal muscle fiber: ultrastructural and molecular aspects. Basic Appl Myol. 2004;14(1):17-21.

10. Berard-Badier M, Pellissier JF, Toga M, Mouillac N, Berard PV. Ultrastructural studies of extraocular muscles in ocular motility disorders. II. Morphological analysis of 38 biopsies. Albrecht Von Graefes Arch Klin Exp Ophthalmol. 1978;208(1-3):193-205.
Clinical Ophthalmology

\section{Publish your work in this journal}

Clinical Ophthalmology is an international, peer-reviewed journal covering all subspecialties within ophthalmology. Key topics include: Optometry; Visual science; Pharmacology and drug therapy in eye diseases; Basic Sciences; Primary and Secondary eye care; Patient Safety and Quality of Care Improvements. This journal is indexed on

Submit your manuscript here: http://www.dovepress.com/clinical-ophthalmology-journal

\section{Dovepress}

PubMed Central and CAS, and is the official journal of The Society of Clinical Ophthalmology (SCO). The manuscript management system is completely online and includes a very quick and fair peer-review system, which is all easy to use. Visit http://www.dovepress.com/ testimonials.php to read real quotes from published authors. 